\title{
Tensile Properties and Constitutive Modeling of Friction Stir Welded AA6061-T6 Butt Joints*
}

\author{
Takashi YOKOYAMA**, Kenji NAKAI**, Eiichi SUKEDAI** \\ and Kazuyoshi KATOH*** \\ ** Department of Mechanical Engineering, Okayama University of Science \\ 1-1 Ridai-cho, Kita-ku, Okayama 700-0005, Japan \\ E-mail: yokoyama@mech.ous.ac.jp \\ *** Department of Mechanical Engineering, College of Industrial Technology, Nihon University \\ 1-2-1 Izumicho, Narashino, Chiba 275-8575, Japan
}

\begin{abstract}
The effect of welding speed on the tensile properties and fracture behavior of friction stir welded AA6061-T6 butt joints was examined. AA6061-T6 sheets of $4.95 \mathrm{~mm}$ in thickness were friction stir welded in the butt joint configuration. The friction stir welding (or FSW) parameters were varied by altering a welding (or travel) speed of a cylindrical tool, keeping its rotational speed constant. Dumbbell-shaped specimens machined from the base material and the FS welded butt joints were used in the tension tests. The rate-independent Ludwik equation was used for the constitutive modeling of their plastic stress-strain behavior. It is shown that the FS welded butt joints exhibit reduced strength and ductility compared with the base material. This reduction is discussed from a microstructural point of view.
\end{abstract}

Key words: AA6061-T6, Constitutive Modeling, Friction Stir Welding, Hardness, Joint Efficiency, Ludwik Equation, Tensile Properties, Welding Speed

\section{Introduction}

Friction stir welding (FSW) is an innovative solid-state joining process developed at The Welding Institute of UK in 1991. This process has great advantages in welding heat-treatable aluminum alloys (such as $2 \mathrm{xxx}, 6 \mathrm{xxx}$ and $7 \mathrm{xxx}$ series) that are often difficult to join by conventional fusion welding. Quite a few successful applications of FSW have been demonstrated in various industries. FSW research into mechanical properties and performance involves microstructure evaluations, weld properties and environmental effects on joint strength. FSW research on process developments includes tool geometry, welding parameter optimization and types of FSW. In addition, research in modeling the FSW process involves material flow modeling and heat transfer analysis. Excellent reviews on FS welding and processing are available in Refs. ${ }^{(1)-(5)}$. As for the FS welded 6xxx series Al alloys, extensive studies have been done with respect to their microstructures ${ }^{(6,7)}$, fatigue properties $^{(8)}$, tensile properties and fracture locations ${ }^{(9,10)}$, the effect of welding parameters on tensile behavior ${ }^{(11,12)}$, the effect of tool geometry on tensile properties ${ }^{(13,14)}$, the effect of post-heat treatment on tensile properties ${ }^{(15)-(17)}$, the influence of dislocation density on strain hardening behavior ${ }^{(18)}$, material flow modeling ${ }^{(19,20)}$ and heat transfer modeling ${ }^{(19,21,22)}$. Nevertheless, the effect of welding parameters on the tensile properties and fracture behavior of the FS welded AA6061-T6 butt joints has not been fully understood, and constitutive modeling studies of the FS welds are scarce, except for Refs. ${ }^{(23,24)}$

The objectives of the present work are to evaluate the tensile properties and to present a

*Received 19 July, 2011 (№. 11-0427) [DOI: 10.1299/jmmp.5.780]

Copyright $\odot 2011$ by JSME 
constitutive modeling of the FS welded AA6061-T6 butt joints. The FS welded butt joints were produced at three different welding speeds, keeping a constant rotational speed of a cylindrical tool. The tensile properties of the base material and the FS welds were measured in an Instron testing machine. The Ludwik constitutive equation was applied to model the measured true tensile stress-plastic strain curves. The experimental results were discussed in terms of the hardness testing and the microstructural examination of the FS welds.

\section{Base Material and Welding Parameter Selection}

The base material used was a commercial aluminum alloy 6061-T6 rolled sheet (320mmx110mmx4.95mm). Its chemical composition is listed in Table 1. A schematic illustration of the FSW process is given in Fig.1, where a specially designed cylindrical tool is rotated counter clock-wise and plunged into the weld line. Figure 2 shows details of the tool with a small diameter threaded probe. FS welded butt joints were fabricated on a position-controlled FSW machine (Nitto Seiki Co., Ltd.: Type FN-II) using welding parameters given in Table 2. The FSW direction was parallel to the rolling direction of the sheet. The sheets were clamped rigidly onto the top of a steel backing plate and were preheated by making the rotating tool stationary for 30 seconds to achieve a sufficient temperature ahead of the tool to allow the travel. Figure 3 gives a picture of typical FS welded AA6061-T6 (FS weld B) butt joint and locations of tension specimen extraction. The relatively higher welding speeds were chosen to obtain higher productivity by making reference to a process window ${ }^{(25)}$ for producing sound welds of four different Al alloys as depicted in Fig. 4. It should be cautioned that the process window cannot be uniquely determined by the combination of the welding parameters alone, depending on the sheet thickness, tool designs, downward force, preheating temperature and so on. In this work, a post-weld aging treatment was not carried out.

Table 1 Chemical composition of AA6061-T6* (mass\%)

\begin{tabular}{ccccccccc}
\hline $\mathrm{Si}$ & $\mathrm{Fe}$ & $\mathrm{Cu}$ & $\mathrm{Mn}$ & $\mathrm{Mg}$ & $\mathrm{Cr}$ & $\mathrm{Zn}$ & $\mathrm{Ti}$ & $\mathrm{Al}$ \\
\hline $0.4-0.8$ & 0.7 & $0.15-0.4$ & 0.15 & $0.8-1.2$ & $0.04-0.35$ & 0.25 & 0.15 & bal. \\
\hline
\end{tabular}

* supplied by Nippon Light Metal Co., Ltd.

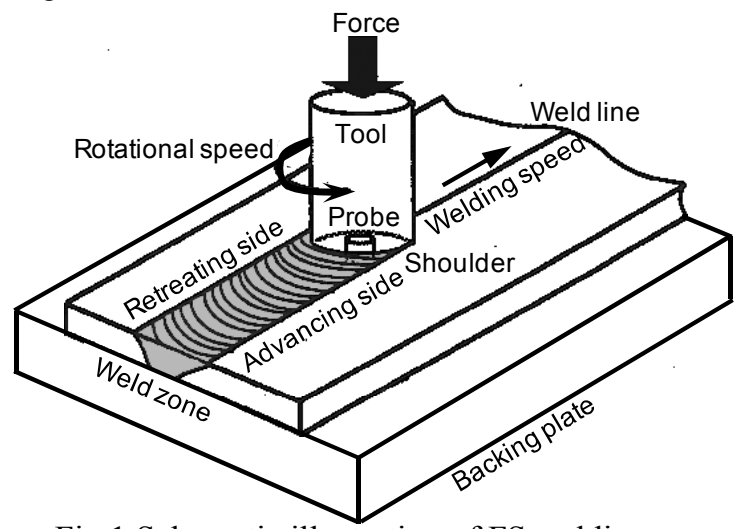

Fig.1 Schematic illustration of FS welding process (backing plate: JIS SS440, thickness $=25 \mathrm{~mm}$ )

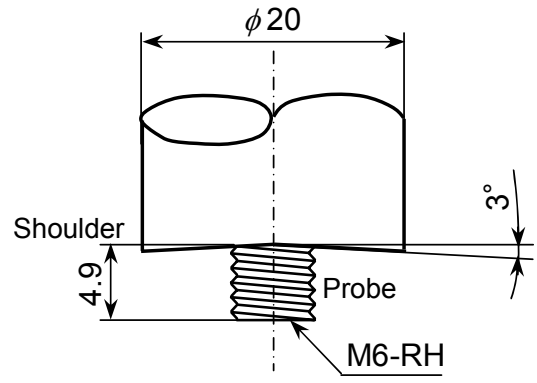

Fig.2 Details of specially designed cylindrical tool (shoulder: JIS SKD61, probe: JIS SCM435) 
Table 2 FSW parameters used for AA6061-T6

\begin{tabular}{c|c|c|c}
\hline FS weld & $\begin{array}{c}\text { Welding speed } \\
v_{\mathrm{t}}(\mathrm{mm} / \mathrm{min})\end{array}$ & $\begin{array}{c}\text { Rotational speed } \\
\omega(\mathrm{rpm})\end{array}$ & $\begin{array}{c}\text { Tool tilt angle } \\
\theta \text { (deg.) }\end{array}$ \\
\hline A & 600 & 2000 & 3 \\
\hline B & 900 & & \\
\hline C & 1200 & & \\
\hline
\end{tabular}

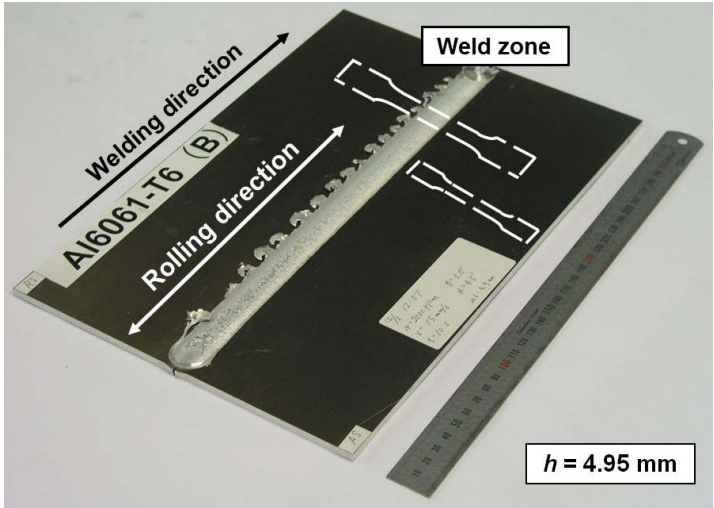

Fig.3 Appearance of FS welded AA6061-T6 butt joint and locations of tension specimen extraction

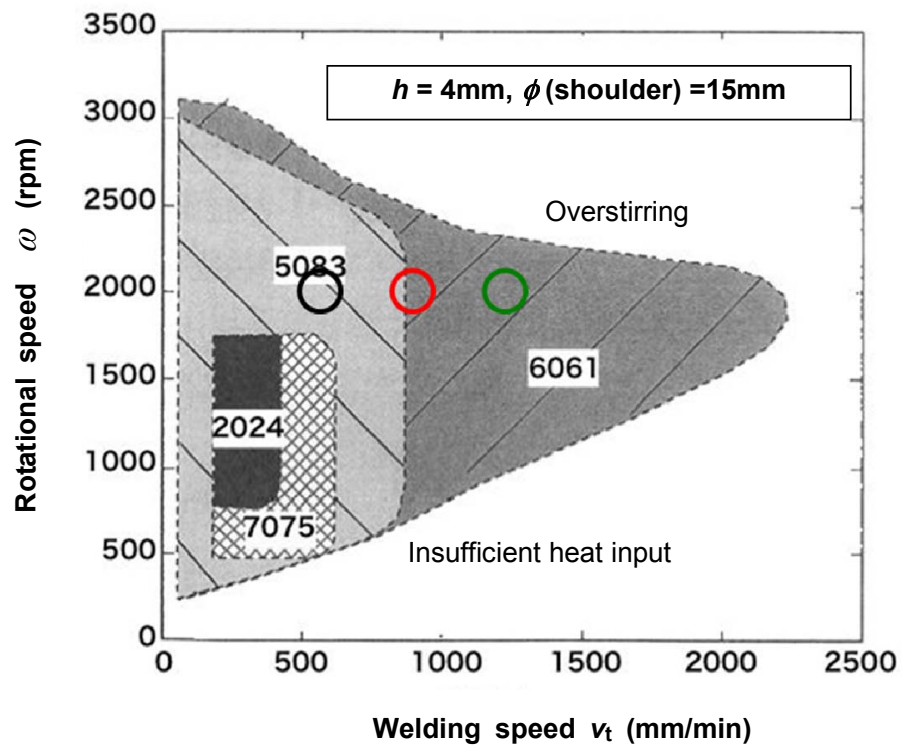

Fig.4 Process window for FSW of four different Al alloys. Three open circles indicate combinations of welding parameters used in this study

\section{Experimental Details}

\subsection{Micro-hardness Testing}

Figure 5 shows optical macrographs of the transverse cross-section of FS welds A, B and $\mathrm{C}$ after etching. As anticipated, the shapes of the weld zone (see Fig. 1) are apparently affected by the welding parameters. In order to examine the microstructural change occurring during the FSW process, micro-hardness tests were carried out with a Vickers hardness tester (Akashi: MVK-H1) with a $200 \mathrm{gf}$ load $(=1.96 \mathrm{~N})$ at an interval of $1 \mathrm{~mm}$. Figure 6 depicts the measured micro-hardness distributions across the three FS welds at a 
distance of $1.65 \mathrm{~mm}$ from the top (or crown) surface. Decreasing welding speed results in the overall decrease in the hardness, which varies through the thickness of the FS welds. The microstructural alteration within the weld zone is separated into three primary "zones". These zones are commonly known as a weld nugget (WN) or a stir zone (SZ), a thermo-mechanically affected zone (TMAZ) and a heat-affected zone (HAZ). The HAZ is not deformed during the FSW process. The hardness is relatively uniform throughout the weld nugget. The minimum in hardness occurring is observed close to the WN/TMAZ boundary mostly on the retreating side.

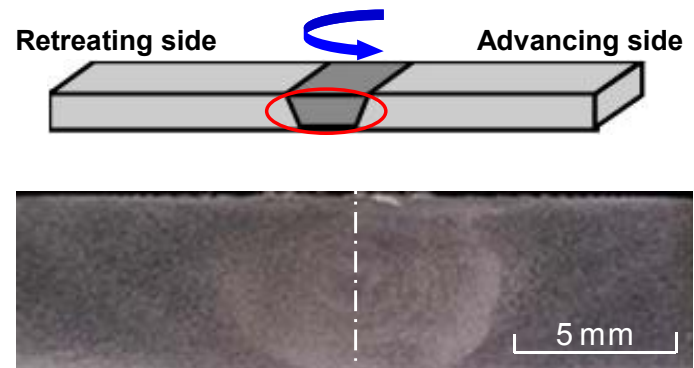

(a) FS weld A: $v_{\mathrm{t}}=600 \mathrm{~mm} / \mathrm{min}$

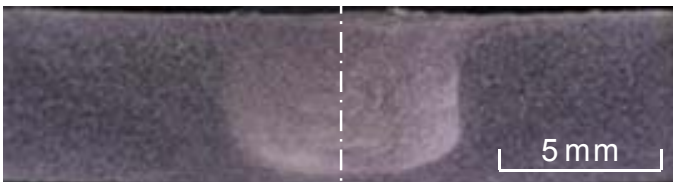

(b) FS weld B: $v_{\mathrm{t}}=900 \mathrm{~mm} / \mathrm{min}$

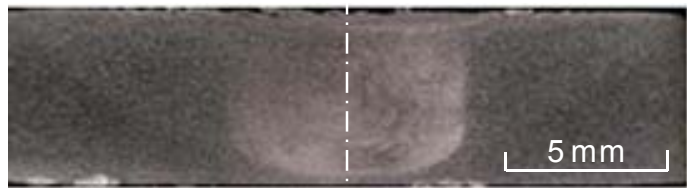

(c) FS weld C: $\quad v_{\mathrm{t}}=1200 \mathrm{~mm} / \mathrm{min}$

Fig.5 Macrostructures of transverse cross-section of FS welds made at three different welding speeds

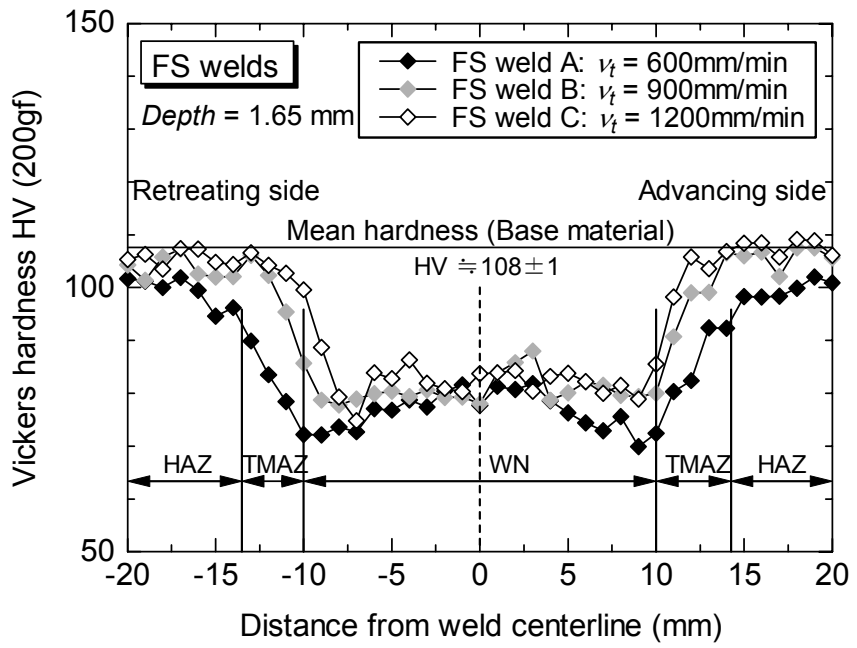

Fig.6 Measured hardness profiles in three different FS welds at depth of $1.65 \mathrm{~mm}$ from top surface 


\subsection{Transverse Tension Testing}

Figure 7 shows two different geometries of transverse tension specimens with a common gage length of $25 \mathrm{~mm}$. The dimensions of the base material specimen (top) were reduced due to size limitations on the AA6061-T6 sheet. The shaded zone indicates the crown surface of the FS welded specimen (bottom) whose gage length section is mostly composed of the WN+TMAZ. To avoid the surface stress concentration, flash on the weld surface was removed by polishing with waterproof abrasive papers prior to testing. Note that the strain to be measured corresponds to an average strain over the gage length. Tension tests were conducted in the Instron testing machine at a crosshead speed of $1 \mathrm{~mm} / \mathrm{min}$. Figure 8 presents typical nominal tensile stress-strain curves for the base material and the FS welds. The tensile strength and ductility of the base material is greatly reduced by FSW process. Note that fine serrations appear on the stress-strain curves of the FS welds just before final fracture. This is partly due to the onset and subsequent development of localized necking near the lowest hardness region in FS welds A and B, and partly due to fracture initiation and propagation at the root surfaces of FS welds B and C (see Fig. 14). The nominal tensile properties of the base material and the three FS welds are summarized in Table 3. and are plotted in Fig. 9 against the welding speed. The proof and tensile strengths of the FS welds remains almost unchanged, while the elongation slightly increases with increasing welding speed. Large variations in the elongations of FS welds B and C are associated with fracture modes, which will be described in Discussion. The joint efficiency of $72 \sim 74 \%$ is almost the same as that for other FS welded AA6061-T6 butt joints given in Refs. ${ }^{(10,12)}$. The fracture locations in the FS welded specimens will be discussed later.

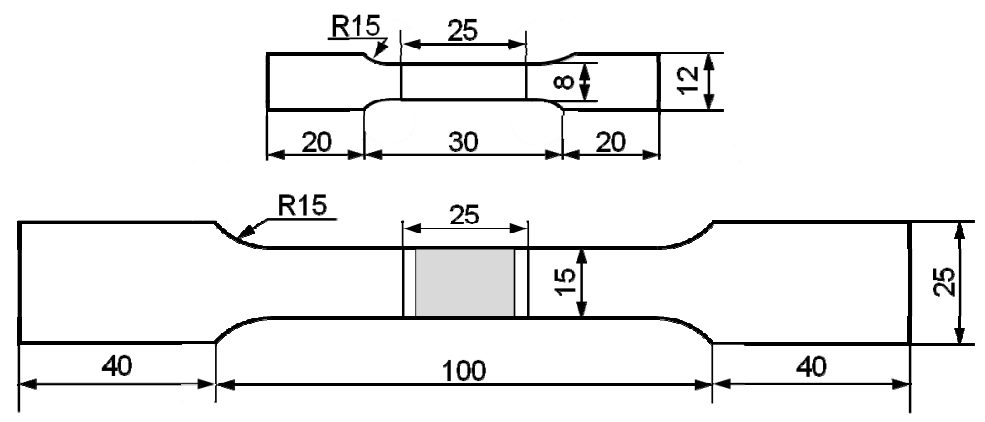

Fig.7 Geometries of transverse tension specimens. Top: base material, bottom: FS welded joint (dimensions in $\mathrm{mm}$ )

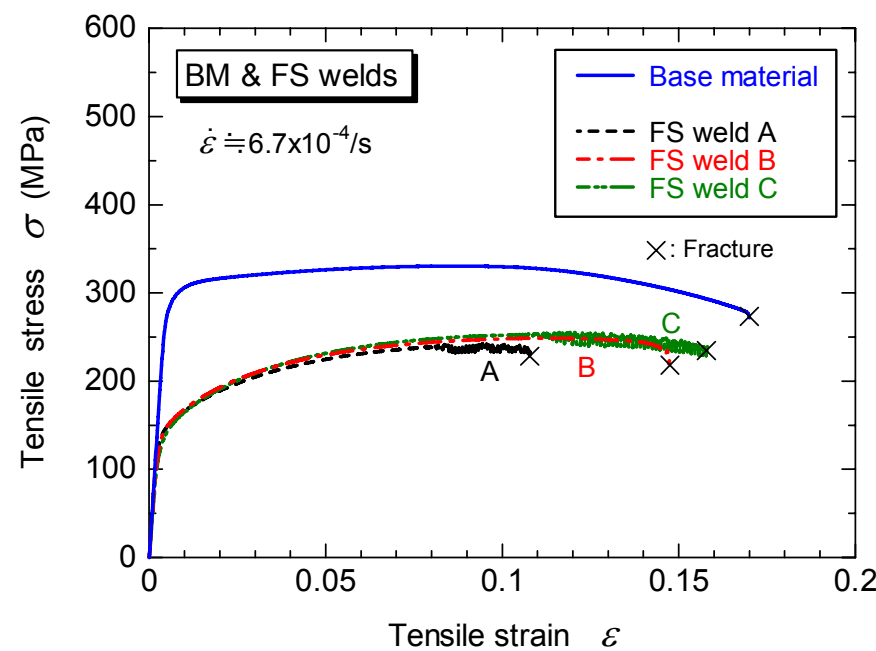

Fig.8 Comparisons of nominal tensile stress-strain curves for base material and three different FS welds 
Table 3 Nominal tensile properties of base material and three different FS welds in transverse direction (gage length $=25 \mathrm{~mm}$ )

\begin{tabular}{ccccc}
\hline $\begin{array}{c}\text { Material } \\
\text { condition }\end{array}$ & $\begin{array}{c}\text { Proof strength } \\
\sigma_{0.2}(\mathrm{MPa})\end{array}$ & $\begin{array}{c}\text { Tensile strength } \\
\sigma_{\text {TS }}(\mathrm{MPa})\end{array}$ & $\begin{array}{c}\text { Elongation } \\
\delta(\%)\end{array}$ & $\begin{array}{c}\text { Joint efficiency } \\
\eta(\%)^{\dagger}\end{array}$ \\
\hline Base material (5) & $295 \pm 6.3^{* *}$ & $326 \pm 8.0$ & $16.4 \pm 0.9$ & - \\
\hline FS weld A (4) & $144 \pm 2.6$ & $236 \pm 4.0$ & $10.3 \pm 0.4$ & 72 \\
\hline FS weld B (4) & $146 \pm 7.1$ & $240 \pm 6.7$ & $11.0 \pm 3.9$ & 74 \\
\hline FS weld C (4) & $143 \pm 3.6$ & $241 \pm 10.4$ & $12.9 \pm 3.5$ & 74 \\
\hline
\end{tabular}

${ }^{*}$ number of specimens, ${ }^{* *}$ mean \pm standard deviation, ${ }^{\dagger} \eta=\left(\sigma_{\mathrm{UTS}, \mathrm{FS} \text { weld }} / \sigma_{\mathrm{UTS}, \mathrm{BM}}\right) \times 100(\%)$

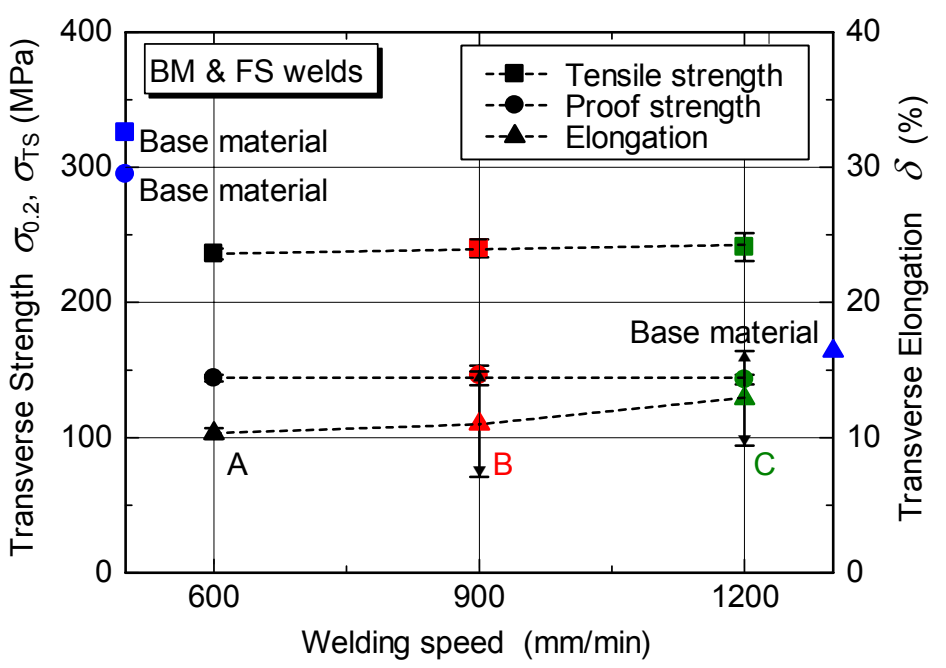

Fig.9 Effect of welding speed on nominal tensile properties of three different FS welds. Note that those of base material are plotted on both vertical axes for comparison. Error bars indicate range of \pm standard deviation given in Table 3.

\subsection{Constitutive Modeling}

We convert the measured nominal stress-strain curves to the corresponding true stress-true strain $(\bar{\sigma}-\bar{\varepsilon})$ curves using the conversion formulas $(\bar{\sigma}=\sigma(1+\varepsilon), \bar{\varepsilon}=\ln (1+\varepsilon))$, which can be then rewritten as the true stress- true plastic strain $\left(\bar{\sigma}-\bar{\varepsilon}_{\mathrm{p}}\right)$ relations for constitutive modeling. In an effort to capture the shape of the true tensile stress-plastic strain curves for the base material and the FS welds, the rate-independent Ludwik relation ${ }^{(26)}$ ( as a special case of the well-known Johnson-Cook constitutive model ${ }^{(27)}$ ) is used, i.e.,

$$
\bar{\sigma}=\sigma_{\mathrm{Y}}+H \bar{\varepsilon}_{\mathrm{p}}{ }^{n}
$$

where $\sigma_{\mathrm{Y}}$ is the yield strength (or the value of $\bar{\sigma}$ at $\bar{\varepsilon}_{\mathrm{p}}=0$ ), $H$ the strength coefficient and $n$ the strain hardening exponent. The following relation can be obtained from Eq. (1):

$$
\bar{\sigma}-\sigma_{\mathrm{Y}}=H \bar{\varepsilon}_{\mathrm{p}}{ }^{n}=H\left(\bar{\varepsilon}-\frac{\bar{\sigma}}{E}\right)^{n}
$$

where $E$ is Young's modulus. Taking logarithms of both sides of Eq. (2) gives

$$
\log \left(\bar{\sigma}-\sigma_{\mathrm{Y}}\right)=n \log \bar{\varepsilon}_{\mathrm{p}}+\log H
$$

Figure 10 indicates two straight lines on a log-log plot for the base material and FS weld A. Performing a linear least-square fit yields the values of $n$ and $H$. The constant $n$ is given as the slope of the linear fit line. The constant $H$ corresponds to the value of $\bar{\sigma}-\sigma_{\mathrm{Y}}$ at $\bar{\varepsilon}_{\mathrm{p}}=$ 1. The parameter values determined for the true tensile stress-plastic strain curves for the base material and the three different FS welds are summarized in Table 4. Note that Young's modulus of FS welds A and B agrees well with that of the base material, while that of the 
FS weld C is slightly lower than that of the base material. This may be because FS weld C contains root flaws in the weld nugget (see Fig.14). The $n$-value of the FS welds is nearly 1.3 times as high as that of the base material. Figure 11 presents typical comparisons between the measured true tensile stress-plastic strain curves and the Ludwik relations for the base material and FS weld A. The true tensile stress-plastic strain behavior before necking initiation is well described by the Ludwik relations. The values of the Ludwik parameters for FS welds $\mathrm{B}$ and $\mathrm{C}$ are not affected by fracture initiation and propagation occurred after necking. Figure 12 shows the strain hardening rate $\mathrm{d} \bar{\sigma} / \mathrm{d} \bar{\varepsilon}_{\mathrm{p}}$ for the base material and the FS welds as a function of the true plastic strain. The strain hardening rate for each FS weld is found to be much higher than that for the base material at any true plastic strain. Such high strain hardening behavior of each FS weld is typically related to the accumulation and interaction of the dislocations during plastic deformation. The low initial dislocation density in the nugget region is believed as the main reason for the high strain hardening for the FS welds ${ }^{(18)}$, which will be explained in Discussion.

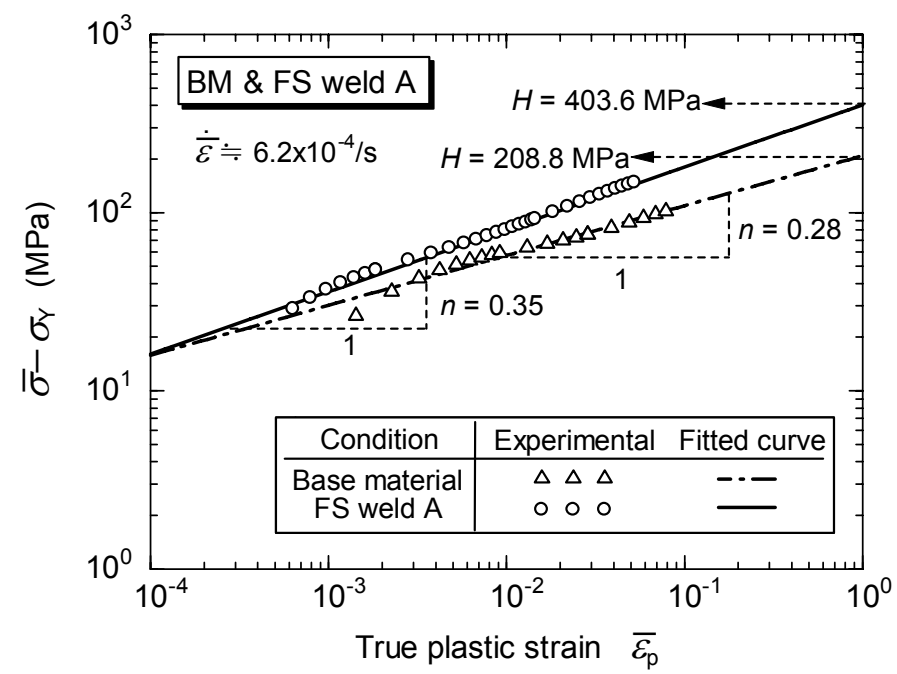

Fig.10 Practical way of determining constants $n$ and $H$ in Ludwik relation

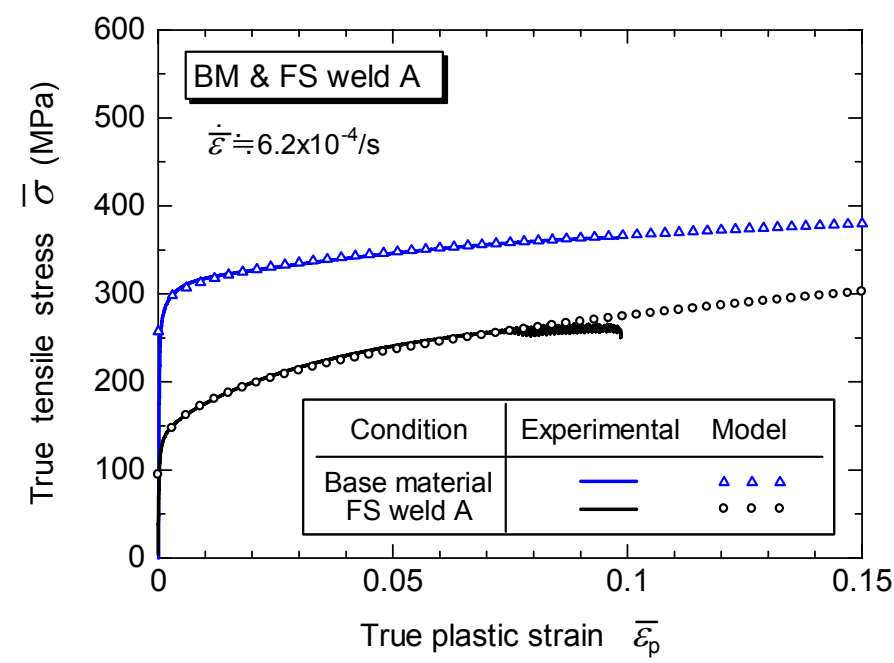

Fig.11 Comparison between measured true tensile stress-plastic strain curves and Ludwik relations for base material and FS weld A 
Table 4 Parameter values for Ludwik relation fitted to true tensile stress-plastic strain data for base material and three different FS welds

\begin{tabular}{|c|c|c|c|c|c|}
\hline Material condition & $\dot{\bar{\varepsilon}}(1 / \mathrm{s})$ & $\sigma_{Y}(\mathrm{MPa})$ & $n(-)$ & $H(\mathrm{MPa})$ & $E(\mathrm{GPa})$ \\
\hline Base material & \multirow{4}{*}{$6.2 \times 10^{-4}$} & 257.3 & 0.28 & 208.8 & 68.2 \\
\hline FS weld $A$ & & 94.8 & 0.35 & 403.6 & 66.5 \\
\hline FS weld B & & 102.5 & 0.34 & 385.4 & 68.8 \\
\hline FS weld C & & 111.8 & 0.36 & 400.5 & 54.7 \\
\hline
\end{tabular}



Fig.12 Strain hardening rate for base material and three different FS welds against true plastic strain before necking

\section{Discussion}

\subsection{Optical Microstructure Observation}

Figure 13 shows typical optical micrographs of the initial base material region, the TMAZ and the weld nugget in FS weld A after etching. It is observed that there is a great difference in the microstructures, or grain shape, grain size and the distribution of strengthening precipitates. The microstructure of the base material region contains coarse elongated (rolled) grains with uniformly distributed strengthening precipitates (mainly $\left.\mathrm{Mg}_{2} \mathrm{Si}{ }^{(13,16,17)}\right)$. The black spots are pits left from etching strengthening precipitates. The TMAZ (b) is characterized by a highly deformed microstructure. The weld nugget (c) consists of very fine, equiaxed grains (a grain size of $5 \sim 10 \mu \mathrm{m}$ ), resulting from the dynamic recrystallization $(\mathrm{DRX})^{(4)}$ that occurred during the FSW process. Grain refinement enhances slightly the flow stress due to the grain-boundary strengthening. Therefore, it is thought that the recovery in the hardness (see Fig. 6) within the weld nugget is caused partly by this grain refinement effect. 


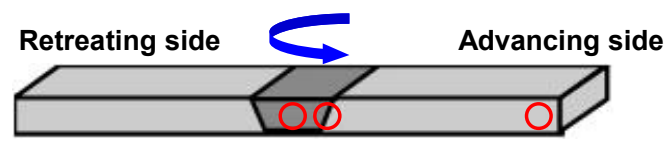

(c) (b)

(a)
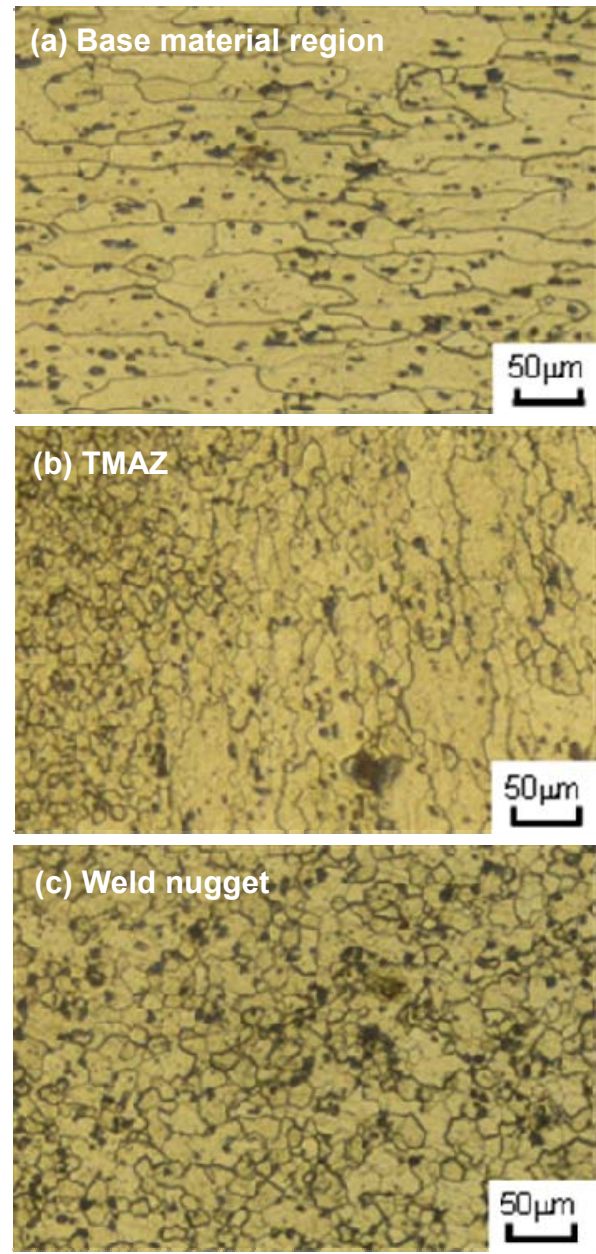

Fig.13 Optical micrographs of (a) base material region, (b) TMAZ and (c) weld nugget in FS weld A

\subsection{SEM Fractography}

Figure 14 shows macroscopic fracture appearance of the tension specimens of the base material and FS welds (A, B, C). The fracture locations or fracture paths greatly vary, depending on the welding speed. Two FS welds A and B failed in a typical shear fracture mode invariably on the retreating side, whereas FS weld $\mathrm{C}$ always failed along a zigzag line starting from a tip of kissing bond ${ }^{(28)}$, which was formed by insufficient breaking-up of the oxide layer on the butted surfaces due to insufficient heat input. Fracture modes occurring in FS welds (A, B, C) were perfectly reproducible. It should be cautioned that the higher welding speed (or low heat input) may produce the FS welds with root flaws. In the present FSW conditions, kissing bonds affect the ductility and fracture modes alone, but it was pointed out in Refs. ${ }^{(29,30)}$ that the presence of kissing bonds (or root flaws) degrades remarkably fatigue lives for AA5083-H321 welds and AA2024-T3 welds. Figure 15 gives the SEM fractographs of the tensile fracture surfaces of the base material and FS weld A specimens. Equiaxed dimples are visible in the base material (a), suggesting a typical ductile tensile fracture. Meanwhile, larger dimples elongated along shear slip planes can be observed in FS weld A (b), suggesting a typical shear fracture near the minimum hardness 
location on the retreating side. The macroscopic facture modes in both tension specimens are consistent with the observed microscopic fracture features. A slight difference exists in the size of the dimples between the base material and FS weld A. This is because FS weld A failed by a shear fracture at the TMAZ/WN boundary.

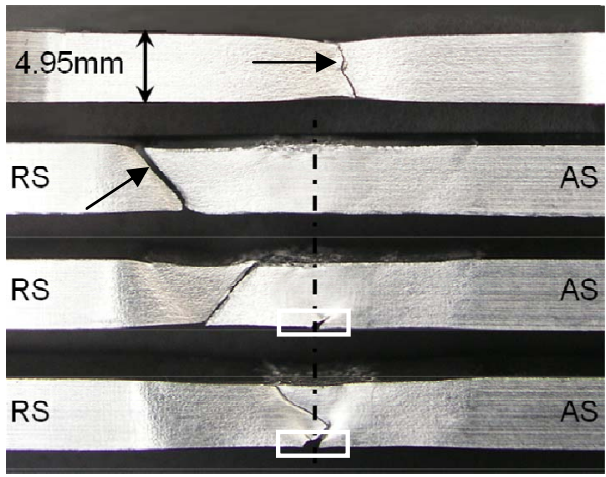

\section{Base material}

FS weld A

FS weld $B$

FS weld C

Fig.14 Tensile fracture appearances of base material (top) and three FS welds A, B and C. Dash-dotted lines indicate weld lines and two arrows indicate directions of SEM observation shown in Fig. 15. Open squares denote non-propagating crack in FS weld B (failed by shear fracture with non-propagating crack) and propagating crack in FS weld C (failed along zigzag line starting from root flaw)
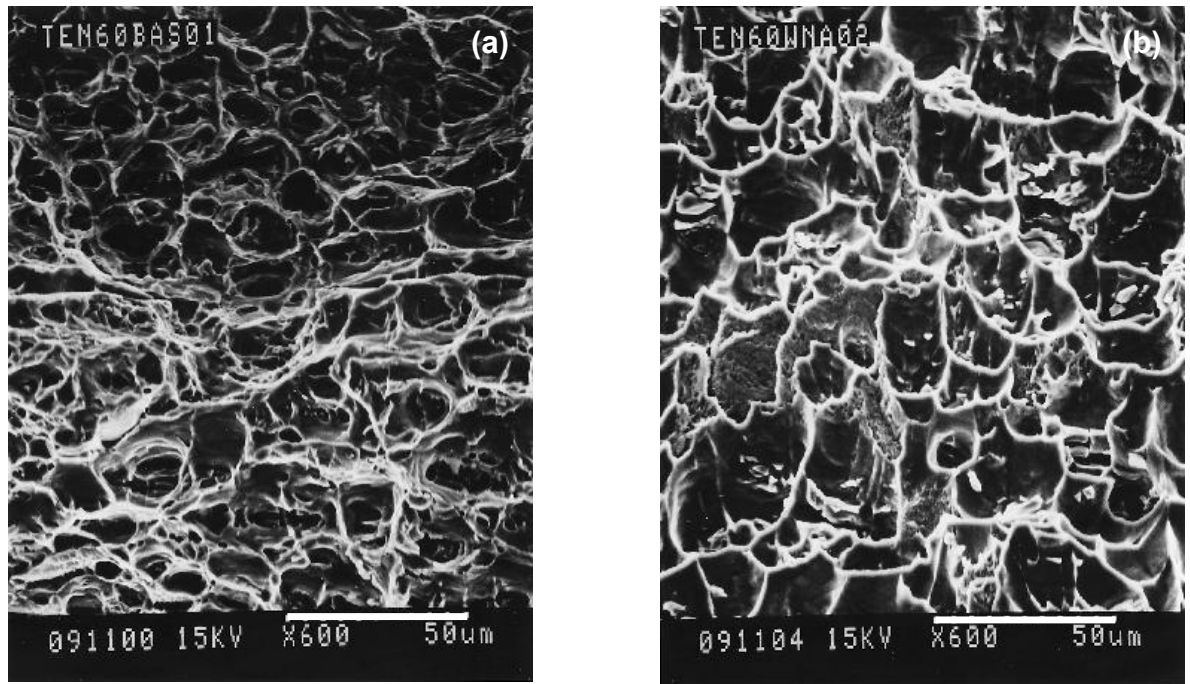

Fig.15 SEM images of specimen fracture surfaces: (a) base material (see arrow in top picture of Fig.14) and (b) FS weld A (see arrow in second top picture of Fig. 14)

\subsection{TEM Microstructure Observation}

In order to further discuss the reduction in the tensile flow stress of the base material due to a thermal cycle of FSW, we examined the microstructures of the base material and the weld nugget in FS weld A with TEM (JEOL: JEM2010F) operated at 200kV. Figure 16 shows the TEM bright-field images of both microstructures. The strengthening precipitates and a high density of dislocations are clearly visible in the base material, whereas dissolution of the precipitates and a low density of dislocations are observed in the weld nugget in FS weld A. It is likely that the flow stress reduction is caused by dissolution/coarsening of the precipitates and the reduction in the dislocation density due to 
the frictional heat and intense plastic deformation during the FSW process ${ }^{(18)}$. The temperature rise around the WN/TMAZ during the FSW process was not directly measured in this work. Murr et al. ${ }^{(7)}$ reported on similar FS welded AA6061-T6 joints made at a welding speed of $120 \mathrm{~mm} / \mathrm{min}$ and a rotational speed of $400 \mathrm{rpm}$ (the revolutionary pitch ${ }^{(9)}$ $v_{\mathrm{t}} / \omega=0.3 \mathrm{~mm} / \mathrm{rev}$ is the same as that for FS weld A) that the maximum temperatures reached in the nugget region were about $425{ }^{\circ} \mathrm{C}$, which is much lower than the solution treatment temperature $530{ }^{\circ} \mathrm{C}$ and the solidus temperature $582{ }^{\circ} \mathrm{C}$ of the base material. Further work is needed to estimate accurately the peak temperatures in the FS welds, which have a great effect on their microstructural evolution.
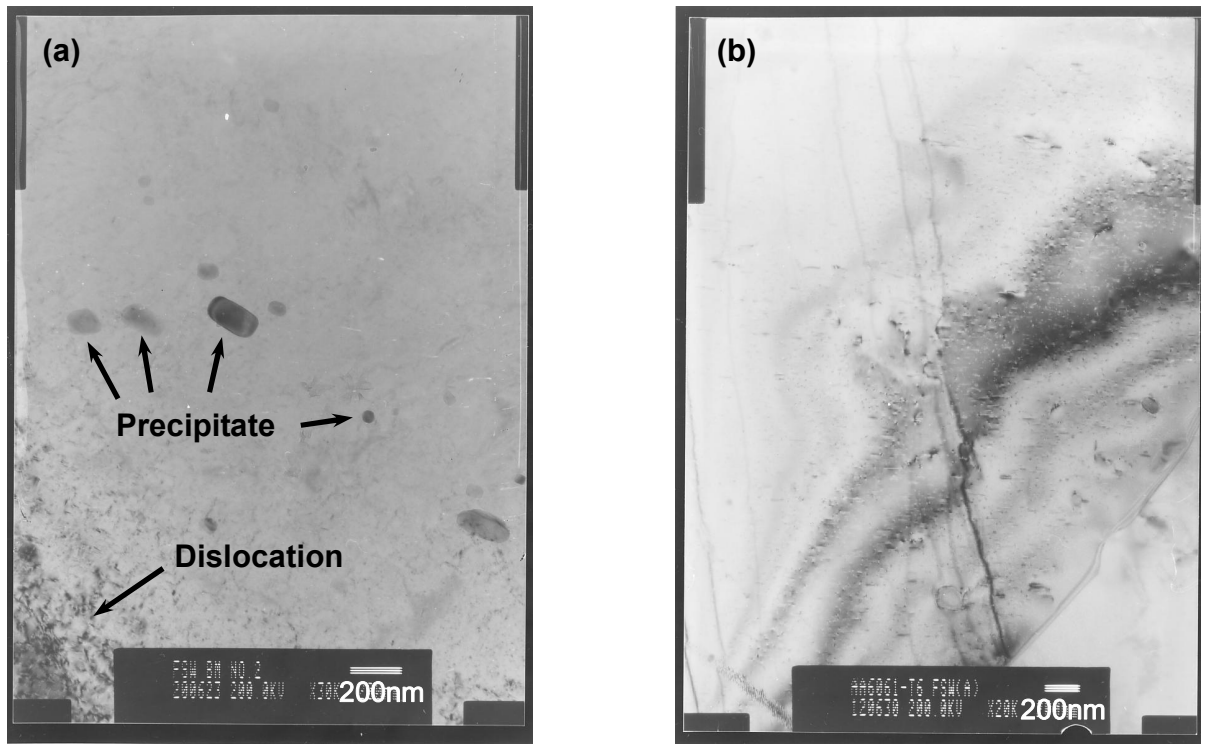

Fig.16 TEM bright-field images of microstructures: (a) base material region and (b) weld nugget in FS weld A

\section{Conclusions}

The tensile properties and fracture behavior of the FS welded AA6061-T6 butt joints fabricated at the three different welding speeds under a constant rotational speed of the cylindrical tool have been evaluated. The Ludwik equation was used for the constitutive modeling of the base material and the FS welds. Their microstructures were analyzed with the help of optical microscopy and scanning electron microscopy. From this investigation, we can conclude the following:

(1) The proof and tensile strengths of the FS welds are hardly affected, while the fracture modes and locations are greatly affected by the welding speeds within the range covered in this study.

(2) The higher welding speeds for achieving higher productivity may produce the FS welds with root flaws, which affect significantly the fracture modes.

(3) The reduced tensile strength and ductility of the FS welds are ascribed to the microstructural evolution that occurred during the FSW process.

(4) The strain hardening rate for each FS weld is far higher than that for the base material.

(5) The rate-independent Ludwik constitutive equation provides a good description of the true tensile stress-plastic strain curves before necking initiation for the base material and the FS welds. 


\section{Acknowledgements}

The authors wish to thank Ryou Hinoue, a graduate student at OUS, for his assistance in the experimental work. The financial support of the Light Metal Educational Foundation Inc., Osaka, Japan, is greatly appreciated.

\section{References}

(1) Mishra, R.S. and Ma, Z.Y., Friction Stir Welding and Processing, Materials Science and Engineering R, Vol.50, (2005), pp.1-78.

(2) Nandan, R., DebRoy, T. and Bhadeshia, H.K.D.H., Recent Advances in Friction-stir Welding - Process, Weldment Structure and Properties, Progress in Materials Science, Vol.53, (2008), pp.980-1023.

(3) Ma, Z.Y., Friction Stir Processing Technology: A Review, Metallurgical and Materials Transactions A, Vol.39, (2008), pp.642-658.

(4) Threadgill, P.L., Leonard, A.J., Shercliff, H.R. and Withers, P. J., Friction Stir Welding of Aluminium Alloys, International Materials Reviews, Vol.54, (2009), pp.49-93.

(5) Murr, L.E., A Review of FSW Research on Dissimilar Metal and Alloy Systems, Journal of Materials Engineering and Performance, Vol.19, (2010), pp.1071-1089.

(6) Liu, G., Murr, L.E., Niou, C-S., McClure, J.C. and Vega, F.R., Microstructural Aspects of the Friction-stir Welding of 6061-T6 Aluminum, Scripta Materialia, Vol.37, (1997), pp.355-361.

(7) Murr, L.E., Liu, G. and McClure, J.C., A TEM Study of Precipitation and Related Microstructures in Friction-stir-welded 6061 Aluminium, Journal of Materials Science, Vol.33, (1998), pp.1243-1251.

(8) Feng, A.H., Chen, D.L. and Ma, Z.Y., Microstructure and Low-cycle Fatigue of a Friction-stir-welded 6061 Aluminum Alloy, Metallurgical and Materials Transactions A, Vol.41, (2010), pp.2626-2641.

(9) Liu, H., Fujii, H., Maeda, M. and Nogi, K., Tensile Properties and Fracture Locations of Friction-stir Welded Joints of 6061-T6 Aluminum Alloy, Journal of Materials Science Letters, Vol.22, (2003), pp.1061-1063.

(10) Lim, S., Kim, S., Lee, C-G. and Kim, S., Tensile Behavior of Friction-stir-welded Al 6061-T651, Metallurgical and Materials Transactions A, Vol.35, (2004), pp.2829-2835.

(11) Ren, S.R., Ma, Z.Y. and Chen, L.Q., Effect of Welding Parameters on Tensile Properties and Fracture Behavior of Friction Stir Welded Al-Mg-Si Alloy, Scripta Materialia, Vol.56, (2007), pp.69-72.

(12) Lakshminarayanan, A.K., Balasubramanian, V. and Elangovan, K., Effect of Welding Processes on Tensile Properties of AA6061 Aluminium Alloy Joints, International Journal of Advanced Manufacturing Technology,Vol.40, (2009), pp.286-296.

(13) Elangovan, K. and Balasubramanian, V., Influences of Tool Pin Profile and Tool Shoulder Diameter on the Formation of Friction Stir Processing Zone in AA6061 Aluminum Alloy, Materials and Design, Vol.29, (2008), pp.362-373.

(14) Elangovan, K., Balasubramanian, V. and Valliappan, M., Effect of Tool Pin Profile and Tool Rotational Speed on Mechanical Properties of Friction Stir Welded AA6061 Aluminum Alloy, Materials and Manufacturing Processes, Vol.23, (2008), pp.251-260.

(15) Krishnan, K.N., The Effect of Post Weld Heat Treatment on the Properties of 6061 Friction Stir Welded Joints, Journal of Materials Science, Vol.37, (2002), pp.473-480.

(16) Elangovan, K. and Balasubramanian, V., Influences of Post-weld Heat Treatment on Tensile Properties of Friction Stir-welded AA6061 Aluminum Alloy Joints, Materials Characterization, Vol.59, (2008), pp.1168-1177.

(17) Reddy, G.M, Mastanaiah, P., Prasad, K.S. and Mohandas, T., Microstructure and Mechanical Property Correlations in AA6061 Aluminum Alloy Friction Stir Welds, Transactions of the Indian Institute of Metals, Vol.62, (2009), pp.49-58. 
(18) Woo, W., Balogh, L., Ungár, T., Choo, H. and Feng, Z., Grain Structure and Dislocation Density Measurements in a Friction-stir Welded Aluminum Alloy using X-ray Peak Profile Analysis, Materials Science and Engineering A, Vol.498, (2008), pp.308-313.

(19) Nandan, R., Roy, G.G. and DebRoy, T., Numerical Simulation of Three-Dimensional Heat Transfer and Plastic Flow During Friction Stir Welding, Metallurgical and Materials Transactions A, Vol.37A, (2006), pp.1247-1259.

(20) Zhang, H.W., Zhang, Z. and Chen, J.T., 3D Modeling of Material Flow in Friction Stir Welding under Different Process Parameters, Journal of Materials Processing Technology, Vol. 183, (2007), pp.62-70.

(21) Song, M. and Kovacevic, R., Numerical and Experimental Study of the Heat Transfer Process in Friction Stir Welding, Proceedings of the Institution of Mechanical Engineers, Vol. 217, Part B: Journal of Engineering Manufacture, (2003), pp. 73-85.

(22) Song, M. and Kovacevic, R., Heat Transfer Modelling for both Workpiece and Tool in the Friction Stir Welding Process: a Coupled Model, Proceedings of the Institution of Mechanical Engineers, Vol. 218, Part B: Journal of Engineering Manufacture, (2004), pp. 17-33.

(23) Liu, S. and Chao, Y. J., Determination of Global Mechanical Response of Friction Stir Welded Plates Using Local Constitutive Properties, Modelling and Simulation in Materials Science and Engineering, Vol.13, (2005), pp.1-15.

(24) Zhang, Z. and Chen, J. T., The Simulation of Material Behaviors in Friction Sir Welding Process by Using Rate-Dependent Constitutive Model, Journal of Materials Science, Vol.43, (2008), pp.222-232.

(25) Nakata, K., Inoki, S., Nagano, Y. and Ushio, M., Friction Stir Welding of $\mathrm{Al}_{2} \mathrm{O}_{3}$ Particulate 6061 Al Alloy Composite, Materials Science Forum, Vols.426-432 (2003), pp.2873-2878.

(26) Ludwik, P., Elemente der Technologischen Mechanik, (1909), Springer, Berlin.

(27) Johnson, G.R. and Cook, W.H., A Constitutive Model and Data for Metals Subjected to Large Strains, High Strain Rates and High Temperatures, Proceedings of $7^{\text {th }}$ International Symposium on Ballistics, Hague, Netherlands, (1983), pp.541-547.

(28) Sato, Y.S., Takauchi, H., Park, S.H.C. and Kokawa, H., Characteristics of the Kissing-bond in Friction Stir Welded Al Alloy 1050, Materials Science and Engineering A, Vol.405, (2005), pp.333-338

(29) Zhou, C., Yang, X. and Luan, G., Effect of Oxide Array on the Fatigue Property of Friction Stir Welds, Scripta Materialia, Vol.54, (2006), pp.1515-1520.

(30) Zhou, C., Yang, X. and Luan, G., Effect of Kissing Bond on Fatigue Behavior of Friction Stir Welds on Al 5083 Alloy, Journal of Materials Science, Vol.41, (2006), pp.2771-2777. 